\title{
AMENAZA DE DIFUNDIR INFORMACIÓN ÍNTIMA: EL CASO QUE AFECTÓ AL CONSERVADOR DE BIENES RAÍCES DE SANTIAGO
}

\author{
ÁlVARO FERNÁNDEZ DÍAZ*
}

\begin{abstract}
RESUMEN: La reciente sentencia que condenó a dos de los acusados por el delito de amenazas en contra del Conservador de Bienes Raíces de Santiago, es una buena oportunidad para referirse a una de las hipótesis delictivas más complejas del ámbito penal, cuya ocurrencia, cuando como medio de presión se utiliza información que involucra la vida íntima de las personas, deja en especial indefensión a las víctimas. En el presente artículo, luego de una breve referencia del bien jurídico comprometido en este tipo de delitos, se buscará determinar la correcta calificación jurídica de los hechos acreditados en el juicio.
\end{abstract}

Palabras clave: Amenaza, chantaje, extorsión, privacidad, intimidad.

ABSTRACT: The recent sentence that condemned two of the defendants for the crime of threats against the "Conservador de Bienes Raíces" of Santiago is a good opportunity to examine one of the most complex criminal hypotheses in the criminal area, i.e.: when information that involves the intimate life of a person is used as a means of pressure, leaving the victim in a state of special defenselessness. The present article, after a brief reference to the juridical good compromised in this type of crimes, seeks to determine the correct juridical qualification of the facts established in trial.

Key words: Threat, blackmail, extortion, privacy, intimacy.

\section{INTRODUCCIÓN}

La reciente sentencia de la Segunda Sala del Cuarto Tribunal de Juicio Oral en lo Penal de Santiago ${ }^{1}$, que condenó a Carolina del Carmen Leal Dapena y a José Marcelo Jadue Sepúlveda por amenazas de un mal que no constituye delito sancionado en el artículo 297 del Código Penal, en relación con el artículo 296 N$^{\circ} 2$ del mismo cuerpo legal, cometidas en contra del Conservador de Bienes Raíces de Santiago, Luis Maldonado Croquevielle, plantea una serie de cuestiones jurídicas que merecen un detenido comentario. Esta es una buena oportunidad para referirse a una de las hipótesis delictivas más complejas del ámbito penal, cuya ocurrencia, cuando como medio de presión se utiliza información que involucra la vida íntima de las personas, deja en especial indefensión a las víctimas. En efecto, la amenaza de divulgación pública de hechos que afecten, por ejemplo, la vida familiar o sexual -cuya captación se ha visto favorecida en

\footnotetext{
* Doctor en Derecho Penal de la Universidad de Sevilla. Profesor de Derecho de la Pontificia Universidad Católica de Chile.

${ }^{1}$ Sentencia del 26 de diciembre de 2007, dictada por la Segunda Sala del Cuarto Tribunal de Juicio Oral en lo Penal de Santiago, integrada por los jueces Pablo Droppelmann Cuneo, María Elisa Tapia Araya y Geni Morales Espinoza, RIT N 153-2007, RUC Nº 0710003705-4.
} 
el último tiempo por los vertiginosos adelantos tecnológicos- ocasiona en algunos casos un malestar psicológico y un pesar mucho mayores que las simples heridas corporales. Estas informaciones pueden dar cuenta de delitos, conductas éticamente reprochables o hechos moralmente intachables, pero que el sujeto, por distintas razones, no quiere dar a conocer a terceros. Naturalmente, las figuras públicas o personas de gran riqueza, dada su posición o medios económicos, son quienes más fácilmente pueden verse expuestas a esta clase de amenazas.

El chantaje -del francés chantage (en inglés se utiliza la expresión extortion o blackmail) - consiste en la "amenaza de pública difamación o daño semejante que se hace contra alguien, a fin de obtener de él dinero u otro provecho" (RAE). En nuestra legislación no contamos con una figura especial con ese nombre, pero pueden aplicarse a su respecto el llamado delito de extorsión (artículo 438 del Código Penal), cuando se obligue a alguien mediante violencia o intimidación a suscribir, entregar u otorgar determinados documentos; el delito consagrado en el artículo 161-B del Código Penal, cuando se amenace a otro con difundir información privada, obtenida en forma ilegal, para conseguir la entrega de dinero o bienes, o la realización de cualquier conducta que no sea jurídicamente obligatoria; o la figura genérica de amenazas condicionales (artículos 296 y ss. del Código Penal), que establece una penalidad distinta si el hecho amenazado constituye o no delito.

De conformidad con la prueba rendida en el juicio, el tribunal tuvo por acreditado los siguientes hechos:

"En los primeros días de febrero de 2007 el abogado José Marcelo Jadue Sepúlveda y Carolina del Carmen Leal Dapena previo concierto, amenazaron a Luis Maldonado Croquevielle con publicitar unas fotos en las que aparecía desnudo, las que Leal Dapena habia obtenido con su autorización en mayo de 1996, con ocasión de haber mantenido una relación sentimental con este; amenaza que concretarian si no pagaba la suma de \$200.000.000, lo que provocaría un daño a la honra de Luis Maldonado, propósito que no fue conseguido"2.

La escasísima frecuencia con que se denuncian y condenan estos delitos -lo que no significa que no ocurran en cantidad apreciable ${ }^{3}-$, y las diversas normas que concurren en nuestro país para sancionar las hipótesis en que se amenaza con la realización de un mal contra una determinada persona para conseguir una prestación, generan dudas sobre la calificación jurídica de estos casos. Esta situación quedó de manifiesto en esta

\footnotetext{
${ }^{2}$ Considerando séptimo de la sentencia comentada.

${ }^{3}$ En el derecho comparado se habla de la existencia de una gran cifra negra, pues en muchos casos es difícil obtener pruebas sobre la ocurrencia de la amenaza (suele ser oral o en forma anónima, y en algunas oportunidades se hace con una aparente legalidad, no obstante ser claro el contenido de la amenaza para la víctima). Además, el afectado suele tener pocos incentivos para denunciar el hecho, toda vez que ello puede implicar dar a conocer públicamente información que prefiere mantener en secreto. Por todos, ver cada uno de esos aspectos en SHAVELL (1993) pp. 1889-1892.
} 
sentencia, donde el Ministerio Público y los querellantes particulares pretendían se aplicara otra figura delictiva (el artículo 161-B del Código Penal).

En el presente artículo, luego de una breve referencia del bien jurídico comprometido en este tipo de delitos, buscaré determinar la correcta calificación jurídica de los hechos acreditados en el juicio, la que, adelanto, no está ni en la postura que pretende sancionarlos por el artículo 161-B del Código Penal, ni tampoco en aquella acogida por la sentencia, que consideró que se trataba de una especie de amenaza de un mal que no constituye delito del artículo 297 del Código Penal, en relación con el artículo $296 \mathrm{~N}^{\circ} 2$ del mismo cuerpo legal.

\section{BIEN JURÍDICO AFECTADO}

En las hipótesis en que se amenaza con la realización de un mal contra una persona -en este caso con la difusión de información consistente en una serie de fotografías íntimas- a cambio de una determinada prestación, se produce una fuerte relación de poder y control del autor sobre la víctima, lo que pone en peligro su libertad de actuación ${ }^{4}$. Esta puesta en peligro de la libertad de las personas puede producirse no solo con las amenazas de un mal constitutivo de delito, sino también cuando se amenaza con males no delictivos, los que en determinados casos, por su fácil realización y lo creíbles que resultan, producen efectos intimidatorios incluso mayores. En efecto, como señala Quintano Ripolles, la amenaza de "males que objetivamente parecen banales, pero de concreción más inmediata, como la de revelar al cónyuge los devaneos de otros, que a veces no constituiría mal delictivo en sí, son bien susceptibles de acarrear efectivas intimidaciones $y$, con ellas, el cumplimiento de condiciones lucrativas para el amenazador".

Esta misma razón sirve para que en EE.UU, distintos autores justifiquen la criminalización del chantaje o blackmail. Así, Solove sostiene que "el blackmail es sancionado penalmente por el fuerte poder de relación que crea. El blackmail permite a una persona ser dominada y controlada por otro. Con el blackmail, el daño no está en la difusión de la información, sino en el control que ejerce quien hace la amenaza (...) Incluso la difusión de la información con que se amenaza puede ser socialmente beneficiosa, ya que puede revelar que la víctima cometió un crimen $u$ otro acto horrendo. Sin embargo, la amenaza de la difusión de información priva tan profundamente del control, que la sociedad todavía desea protegernos en contra de ella"6.

En ese mismo sentido Fletcher, quien, refiriéndose a casos semejantes al de esta sentencia que comentamos, afirma que cuando el blackmail ocurre, la víctima sabe que aunque pague al chantajista este "puede repetir la demanda en el futuro" 7 . En efecto,

\footnotetext{
${ }^{4}$ En todo caso, cabe consignar que las amenazas condicionales representan delitos de peligro concreto, ya que no requieren que el autor haya conseguido la conducta que perseguía de la víctima. Por todos, ver LARRAURI (1987) pp. 575 y ss.

${ }^{5}$ QUiNTANO RIPOLLES (1962) p. 933.

${ }^{6}$ SOLOVE (2006) pp. 543-544.

7 FLETCHeR (1993) p. 1626.
} 
nada impide, por ejemplo, que el chantajista tenga otras copias de las fotografías y pueda demandar más dinero con posterioridad. Incluso si ello no fuera cierto, y no tuviera en su poder otras copias, la víctima seguirá considerándolo como una posibilidad, y ese estado de la víctima del chantaje "la coloca en una posición de permanente subordinación" 8 .

Es por ello que uno no puede sino compartir lo sostenido en uno de los leading cases de la jurisprudencia británica, cuando se sostiene que "en el listado de las ofensas criminales, el blackmail es una de las peores, porque lo que en realidad envuelve, muy frecuentemente, es un atentado de asesinar el alma, y se hace precisamente eso (...) cuando para reforzar una demanda, se usa algo que ella (en este caso la víctima) tenía derecho a creer que era privado..."9.

\section{EL CONSENTIMIENTO EN LA CAPTACIÓN DE LA IMAGEN EXCLUYE EL CHANTAJE DEL ARTÍCULO 161-B DEL CÓDIGO PENAL}

La Ley $\mathrm{N}^{\circ}$ 19.423, publicada el 20 de noviembre de 1995, introdujo dos nuevos artículos en el Código Penal: el artículo 161-A que sanciona diversos atentados en contra de la intimidad, que en términos generales se refieren a la captación y difusión de información privada en los términos que en esa disposición se indica, y el artículo 161-B que, vinculado a la norma anterior, contiene una figura especial de chantaje. Así, dichos artículos establecen:

Artículo 161-A. "Se castigará con la pena de reclusión menor en cualquiera de sus grados y multa de 50 a 500 Unidades Tributarias Mensuales al que, en recintos particulares o lugares que no sean de libre acceso al público, sin autorización del afectado y por cualquier medio, capte, intercepte, grabe o reproduzca conversaciones o comunicaciones de carácter privado; sustraiga, fotografie, fotocopie o reproduzca documentos o instrumentos de carácter privado; o capte, grabe, filme o fotografie imágenes o hechos de carácter privado que se produzcan, realicen, ocurran o existan en recintos particulares o lugares que no sean de libre acceso al publico.

Igual pena se aplicará a quien difunda las conversaciones, comunicaciones, documentos, instrumentos, imágenes y hechos a que se refiere el inciso anterior.

En caso de ser una misma la persona que los haya obtenido y divulgado, se aplicarán a esta las penas de reclusión menor en su grado máximo y multa de 100 a 500 Unidades Tributarias Mensuales.

Esta disposición no es aplicable a aquellas personas que, en virtud de ley o de autorización judicial, estén o sean autorizadas para ejecutar las acciones descritas".

\footnotetext{
${ }^{8}$ FLETCHER (1993) p. 1626.

9 R v. Hadjou, Court of Appeal Criminal Division, 20 de enero de 1989. Este caso se trataba de un acusado que tuvo una relación con una mujer, en el curso de la cual grabaron en video sus actos sexuales. Cuando terminó la unión entre ellos, él le entregó a ella los originales de las grabaciones, pero se dejó para sí una serie de copias. Con posterioridad la amenazó con remitir copias del video a distintas personas, si no le pagaba la suma de dos mil libras. Sobre esta importante sentencia, ver ALLDRIDGE (1993) pp. 382-383.
} 
Artículo 161-B. "Se castigará con la pena de reclusión menor en su grado máximo y multa de 100 a 500 Unidades Tributarias Mensuales al que pretenda obtener la entrega de dinero o bienes o la realización de cualquier conducta que no sea jurídicamente obligatoria, mediante cualquiera de los actos señalados en el articulo precedente. En el evento que se exija la ejecución de un acto o hecho que sea constitutivo de delito, la pena de reclusión se aplicará aumentada en un grado".

Como señalé anteriormente, tanto el Ministerio Público como la parte querellante solicitaron al tribunal se aplicara la figura especial de chantaje consagrada en el artículo 161-B del Código Penal, en relación con el artículo 161-A del mismo texto legal. A su juicio, en este caso, se buscaba obtener la entrega de dinero amenazando con la difusión de unas fotografías. Sin embargo, comparto el argumento dado por el tribunal en su sentencia para rechazar esa pretensión, pues como bien se señala en el fallo: "el tipo penal por el cual acusó el Ministerio Público y la parte querellante, del artículo 161 letra $B$ en relación con el artículo 161 letra $A$ del Código Penal, tiene como requisito esencial que las fotos por las cuales se pretende obtener la entrega de dinero, con el objeto de evitar que se difundan, hayan sido obtenidas sin autorización del afectado, cuyo no es el caso en estudio, pues la víctima autorizó la toma de ellas" 10 .

En efecto, el inciso segundo del artículo 161-A sanciona al que "difunda (...) las imágenes y hechos a que se refiere el inciso anterior", y ese inciso anterior exige que se hayan tomado "sin autorización del afectado". Pretender limitar este requisito únicamente a las hipótesis del inciso primero del artículo 161-A, es desconocer una remisión expresa de ley que no admite excepciones ${ }^{11}$. Por eso, sostener que la remisión se circunscribiría únicamente a los aspectos materiales del inciso primero, pero no a lo relativo a la falta de autorización, implica extender más allá de lo permitido el ámbito de aplicación de una norma, lo que viola el principio de legalidad. En ese mismo sentido el fallo cuando sostiene que "de la simple lectura de los artículos 161 A y $161 \mathrm{~B}$ del Código Penal aparece que la no autorización de la victima es un hecho descrito por el tipo penal en sus múltiples hipótesis, por lo que no procede desatender el tenor literal de la norma a pretexto de consultar su espiritu como pretenden las partes acusadoras" 12 .

\section{AMENAZAS CONDICIONALES}

\section{DECISIÓN DEL TRIBUNAL: AMENAZA DE UN MAL QUE NO CONSTITUYE DELITO}

En su sentencia, luego de rechazar la aplicación de la figura especial de chantaje del artículo 161-B del Código Penal, el tribunal resolvió condenar a los acusados por el

\footnotetext{
${ }^{10}$ Considerando octavo de la sentencia comentada.

11 En este sentido ver POlitoff, Matus y RAMíRez (2006), pp. 234-240, quienes sin pronunciarse expresamente sobre este punto, hacen aplicable la exigencia de la falta de consentimiento a todas las conductas del artículo 161-A. Incluyen, por tanto, la del inciso segundo de dicha disposición, que sanciona la difusión de imágenes.

12 Considerando octavo de la sentencia comentada.
} 
delito de amenazas de un mal que no constituye delito, sancionado en el artículo 297 del Código Penal, en relación con el artículo $296 \mathrm{~N}^{\circ} 2$ del mismo cuerpo legal. Dichas disposiciones establecen:

Artículo 297. "Las amenazas de un mal que no constituya delito hechas en la forma expresada en los números 1 o 2 del artículo anterior, serán castigadas con la pena de reclusión menor en sus grados minimo a medio".

Artículo 296. $\mathrm{N}^{\circ} 2$ "Con presidio menor en sus grados minimo a medio, si hecha la amenaza bajo condición el culpable no hubiere conseguido su propósito".

Para la aplicación de este delito, el tribunal en su sentencia no hace un mayor análisis sobre las características típicas de esta compleja figura delictiva. Únicamente se limita a consignar que "el tipo penal de amenaza exige, como requisitos para su configuración, causar un mal a una persona o a su familia, honra o propiedad, que sea seria (sic) y verosimil' 13 . No hay, por tanto, ningún razonamiento de por qué se consideró que se trataba de la amenaza de un mal no delictivo, y de cuáles razones, por ende, lo llevaron a descartar la figura de amenazas de un mal delictivo (artículo 296 del Código Penal).

Por otra parte, si el tribunal consideró que se trataba de la amenaza de un mal no delictivo, hubiera sido esperable que consignara qué características tenía ese mal (¿se trataba de la amenaza de ejecutar un mal lícito?). Con ello, el tribunal no entra al aspecto más complejo del delito de amenazas de un mal no delictivo: cómo justificar la sanción penal de aquellos casos en que se amenaza con ejecutar una conducta lícita (ejemplo, denunciar la participación en un delito o contarle a la esposa la infidelidad del marido), para conseguir una prestación también lícita (ejemplo, entrega de una cantidad de dinero u otras especies). Pensemos en el siguiente ejemplo de chantaje: "Si no me das 100 mil pesos, denunciaré al Servicio de Impuestos Internos que falsificaste tu declaración tributaria”. Aquí, la denuncia es perfectamente lícita, más aún, es deseable, y la prestación solicitada también es lícita (dar dinero). A ello se le denomina la "paradoja del chantaje": en algunos casos, cabe admitir la criminalización de una conducta que está compuesta de dos actos lícitos en sí mismos ${ }^{14}$. Lo relevante no es si el mal o la exigencia son lícitos o no, sino si existe una correlación entre el mal con que se amenaza y la exigencia que se impone. Así, podrá configurarse un delito cuando, en virtud de ese derecho con cuyo ejercicio se amenaza (ejemplo, denunciar un delito o contarle a la

\footnotetext{
${ }^{13}$ Considerando octavo de la sentencia comentada.

14 En favor de penalizar estas hipótesis se ha manifestado, con razón, la abrumadora mayoría de la jurisprudencia y doctrina en el derecho comparado (en nuestro derecho no han recibido todavía la suficiente atención de nuestra doctrina y jurisprudencia), toda vez que la circunstancia de que el amenazador esté facultado para ejecutar el hecho que anuncia a su víctima, no es suficiente por sí sola para estimar que su conducta esté legitimada si agrega cualquier condición. Por todos, y acogiendo diversos fundamentos para criminalizar este tipo de conductas, ver en España Rodríguez DEVEZA (1975) pp. 261-262; SERRANo GonzÁlez de Murillo (1991) pp. 421-447; Muñoz Conde (2004)pp. 165-167; en Estados Unidos FletCHer (1993) pp. 1617-1638; KATZ (1996) pp.133-195.
} 
esposa la infidelidad del marido), no se está facultado para exigir la conducta a que la condición se refiere (por ejemplo, exigir la entrega de dinero) ${ }^{15}$.

De cualquier forma, entrar a ese apasionante debate -sobre la denominada "paradoja del chantaje” y el ámbito de aplicación del artículo 297 del Código Penal- no era necesario en este caso, pues la amenaza de difundir (el tribunal en su sentencia habla de "publicitar") las fotografías materia del proceso, es una amenaza de un hecho delictivo y, por tanto, debió aplicarse la figura del artículo 296 del Código Penal.

\section{DECISIÓN CORRECTA: AMENAZA DE UN MAL QUE CONSTITUYE DELITO}

El delito de amenaza de un mal que constituye delito está sancionado en el artículo 296 del Código Penal. Dicha disposición señala:

Artículo 296. "El que amenazare seriamente a otro con causar a él mismo o a su familia, en su persona, honra o propiedad, un mal que constituya delito, siempre que por los antecedentes aparezca verosimil la consumación del hecho, será castigado:

1. Con presidio menor en sus grados medio a máximo, si hubiere hecho la amenaza exigiendo una cantidad o imponiendo ilegitimamente cualquiera otra condición y el culpable hubiere conseguido su propósito.

2. Con presidio menor en sus grados minimo a medio, si hecha la amenaza bajo condición el culpable no hubiere conseguido su propósito.

3. Con presidio menor en su grado mínimo, si la amenaza no fuere condicional; a no ser que merezca mayor pena el hecho consumado, caso en el cual se impondrá esta.

Cuando las amenazas se hicieren por escrito o por medio de emisarios, estas se estimarán como circunstancias agravantes.

Para los efectos de este artículo se entiende por familia el cónyuge, los parientes en la linea recta de consanguinidad o afinidad legitima, los padres e hijos naturales y la

15 En nuestra legislación, el delito de amenazas condicionales de un mal que no constituye delito (artículo 297 del Código Penal) admite perfectamente sancionar este tipo de casos, en que se amenaza con ejecutar una conducta lícita en sí misma para conseguir una prestación también lícita. Ello ha quedado reafirmado con la reforma introducida por la Ley $\mathrm{N}^{\circ} 19.659$ (diciembre de 1999) que, entre varias modificaciones a este delito, sustituyó en el artículo $296 \mathrm{~N}^{\circ} 1$ del Código Penal (norma a la cual se remite el artículo 297) la expresión "imponiendo cualquiera otra condición ilícita" por la de "imponiendo ilegitimamente cualquiera otra condición". Así, el Informe de la Comisión de Constitución, Legislación y Justicia y Reglamento del Senado, al justificar este cambio, da un fuerte argumento de la historia de nuestra ley en el sentido de que, para pronunciarse sobre la ilegitimidad de la conducta, no puede el juzgador considerar de forma aislada las características del mal con que se amenaza o la condición que se impone, sino que debe analizarlos uno en relación con la otra. En dicho Informe se señala: "De esta forma, se elimina el requisito de la ilicitud de la condición impuesta bajo amenaza, que actualmente exige este número, por la voz 'ilegitima', ya que el concepto de 'condición ilícita' admite diversas interpretaciones, algunas de las cuales son abiertamente incongruentes con el fin de la norma. El término 'ilegitimamente', en cambio, recoge la interpretación que resulta más acorde con el sentido de la disposición, esto es, que la ilicitud de la condición se determina en relación con el mal cuya irrogación se amenaza. Asi, ilícitas son las condiciones que no pueden imponerse bajo ciertas amenazas; vale decir, la ilegitimidad está relacionada con la acción de imponer la condición bajo amenaza, y no tan solo con el eventual contenido de esa condición" (Boletín $\mathrm{N}^{\circ}$ 1.990-03). 
descendencia legitima de estos, los hijos ilegitimos reconocidos y los colaterales hasta el tercer grado de consanguinidad o afinidad legitimas".

En este caso en particular, la amenaza de "publicitar unas fotos en las que aparecía desnudo" 16 que según la propia sentencia "provocaría un daño a la honra de Luis Maldonado" 17 , constituye una amenaza de un mal delictivo: de un delito de injurias ${ }^{18}$. De conformidad con el artículo 416 del Código Penal, es injuria "toda expresión proferida o acción ejecutada en deshonra, descrédito o menosprecio de otra persona". El bien jurídico protegido en este delito es el honor, es decir, el mismo interés que la propia sentencia, con razón, estimó que se vería afectado. Además, ese bien jurídico está expresamente mencionado en el encabezado del artículo 296 del Código Penal cuando se señala que se puede amenazar "a otro con causar a él mismo o a su familia, en su persona, honra o propiedad, un mal que constituya delito".

Por otra parte, este caso es precisamente uno de aquellos en que tratándose de injurias no se admite la prueba de la verdad (la denominada exceptio veritatis), por carecer la divulgación de las fotos de todo interés público. En efecto, si se aplican las normas sobre las injurias consagradas en el Código Penal, rige el artículo 420 que sostiene que al "acusado de injuria no se admitirá prueba sobre la verdad de las imputaciones, sino cuando estas fueren dirigidas contra empleados públicos sobre hechos concernientes al ejercicio de su cargo". Circunstancia esta, que evidentemente no se da en los hechos acreditados en el juicio. Por otra parte, si se aplican las normas contenidas en la Ley $\mathrm{N}^{\circ}$ 19.733 -en la medida en que se amenazare con la divulgación de las fotografías por un medio de comunicación social- rige el artículo 30 de dicho texto, el que señala que al "inculpado de haber causado injuria a través de un medio de comunicación social, no le será admitida prueba de verdad acerca de sus expresiones, sino cuando hubiere imputado hechos determinados y concurrieren a lo menos una de las siguientes circunstancias: a) Que la imputación se produjere con motivo de defender un interés público real; b) Que el afectado ejerciere funciones públicas y la imputación se refiriere a hechos propios de tal ejercicio". A mayor abundamiento, el inciso final del referido artículo 30 expresamente considera como pertinentes a la esfera privada de las personas, y que por ende carecen de interés público, "los hechos relativos a su vida sexual, conyugal, familiar o doméstica, salvo que ellos fueren constitutivos de delito". Es decir, no caben dudas que en el caso en estudio, se trata de una hipótesis característica de injuria respecto de la cual no se admite la prueba de la verdad.

Por todo lo anterior, y tendiendo en consideración los hechos acreditados en el juicio, el tribunal debió aplicar la figura del artículo $296 \mathrm{~N}^{\circ} 2$ del Código Penal, la amenaza de un mal constitutivo de delito (injurias), relativa a las hipótesis en que "hecha

\footnotetext{
16 Considerando séptimo de la sentencia comentada.

17 Considerando séptimo de la sentencia comentada.

${ }^{18}$ En el derecho español, por ejemplo, que mantiene la distinción entre amenazas de un mal que constituye delito y amenazas de un mal que no constituye delito, la doctrina expresamente ha consignado que si la amenaza de difundir hechos referentes a la vida privada afecta el honor de la víctima, estaríamos en presencia de la amenaza de un mal delictivo (injurias). Por todos, ver JAREÑO LEAL (1997) pp. 91-92.
} 
la amenaza bajo condición el culpable no hubiere conseguido su propósito". La penalidad para esta clase delitos, por no haberse logrado el objetivo de la entrega del dinero, es de presidio menor en sus grados mínimo a medio. Esa penalidad, en todo caso, es similar a la consignada para las amenazas de un mal que no constituye delito del artículo 297 del Código Penal, que establece una sanción de reclusión menor en sus grados mínimo a medio. Sin embargo, donde sí tiene efectos en la penalidad hacer la distinción entre amenazas condicionales de un mal constitutivo de delito y de un mal no constitutivo de delito, y por eso la conclusión de este comentario no es solo una disquisición doctrinaria, es en aquellos casos en que el culpable ha logrado su propósito. Aquí, de conformidad con el artículo $296 \mathrm{~N}^{\circ} 1$ del Código Penal, la sanción para las amenazas de un mal constitutivo de delito es de presidio menor en sus grados medio a máximo, mientras que las amenazas de un mal que no constituye delito del artículo 297, mantienen su penalidad de reclusión menor en sus grados mínimo a medio.

\section{BIBLIOGRAFÍA CITADA}

ALLDRIDGE, Peter (1993): “Attempted murder of the soul': Blackmail, privacy and secrets", Oxford Journal of Legal Studies, vol. $13 \mathrm{~N}^{\circ} 3$ : pp. 368 y ss.

FLETCHER, George (1993): "Blackmail: The paradigmatic crime", University of Pennsylvania Law Review, vol. $141 \mathrm{~N}^{\circ}$ 5: pp. 1617 y ss.

Jareño Leal, Ángeles (1997): Las amenazas y el chantaje en el Código Penal de 1995 (Editorial Tirant lo Blanch, Valencia).

KaTZ, Leo (1996): Evasion, Blackmail, Fraud, and Kindred Puzzles of the Law (Editorial The University of Chicago Press, Chicago).

LARRAURI, Elena (1987): “Consideraciones sobre el bien jurídico protegido en el delito de amenazas", Cuadernos de Politica Criminal, N³3: pp. 563 y ss.

Muñoz Conde, Francisco (2004): Derecho Penal. Parte Especial (Editorial Tirant lo Blanch, Valencia).

Politoff, Sergio; Matus, Jean Pierre y Ramírez, María Cecilia (2006): Lecciones de Derecho Penal Chileno. Parte Especial (Editorial Jurídica de Chile, Santiago).

Quintano Ripolles, Antonio (1962): Tratado de la Parte Especial del Derecho Penal (Editorial Revista de Derecho Privado, Madrid) tomo I.

Rodríguez Deveza, José María (1975): Derecho Penal Español. Parte Especial (Madrid). Serrano GonzÁlez De Murillo, José Luis (1991): "El injusto de las amenazas condicionales con mal no delictivo (criterio de delimitación)", Cuadernos de Política Criminal, $\mathrm{N}^{\circ}$ 44: pp. 421 y ss.

SHAVELL, Steven (1993): "An economic analysis of threats and their illegality: Blackmail, Extortion and Robbery", University of Pennsylvania Law Review, vol. $141 \mathrm{~N}^{\circ} 5$ : pp. 1877 y ss.

Solove, Daniel (2006): "A Taxonomy of privacy", University of Pennsylvania Law Review, vol. $154 \mathrm{~N}^{\circ}$ 3: pp. 477 y ss. 
